\title{
GESTIÓN Y CONSERVACIÓN DE DOCUMENTOS FOTOGRÁFICOS EN EL TERCER SECTOR: EXPERIENCIA DE LA FUNDACIÓN VICENTE FERRER
}

\author{
Juan Alonso-Fernández
}

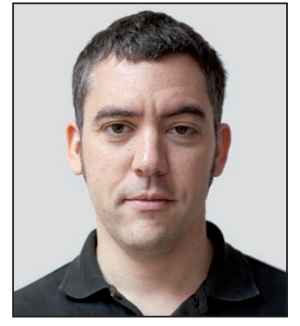

Juan Alonso-Fernández, especialista en documentación fotográfica, es licenciado en historia por la Universitat Autònoma de Barcelona $(U A B)$ y licenciado en documentación por la misma universidad. Actualmente está cursando la licenciatura de comunicación audiovisual en la Universitat Oberta de Catalunya (UOC). Es autor del blog "Documentación fotográfica" y colabora en RecBib con artículos sobre la gestión de la imagen fija. Trabaja desde 2008 en la Fundación Vicente Ferrer, en las áreas de documentación fotográfica y audiovisual.

Fundación Vicente Ferrer París, 71 - 3‥ 08029 Barcelona jalonso@fundacionvicenteferrer.org http://documentacionfotografica.blogspot.com

\section{Resumen}

En el Tercer Sector la fotografía es doblemente importante: por su carácter documental y por la responsabilidad social de las ONGs a la hora de mostrar la imagen de los países en vías de desarrollo. La revolución digital incrementa la producción y el consumo de documentos visuales y los píxeles irrumpen en el archivo modificando equipos y obligando a considerar nuevos modelos de funcionamiento. Se exponen los procedimientos de trabajo de un archivo fotográfico del Tercer Sector desde la perspectiva de la experiencia en la Fundación Vicente Ferrer. Se explica la gestión de la imagen digital en un departamento de comunicación de una ONG para el desarrollo.

\section{Palabras clave}

ONG, ONGD, Tercer Sector, Documentación fotográfica, Archivos fotográficos, Inmagic, Fundación Vicente Ferrer, Fotografía, Imágenes digitales, Gestión fotográfica, Edición gráfica.

Title: Management and conservation of photographic documentation in the Third Sector: the experience in the Vicente Ferrer Foundation

\section{Abstract}

In the Third Sector photography is doubly important: because of the documentary character of photography and because of the social responsibility of NGOs when it comes to portraying the image of developing countries. The digital revolution increases production and consumption of visual documents and pixels burst into the photo archives, which makes it necessary to change equipments and consider new working models. The working procedures of a photo archive of the Third Sector are developed from the perspective of the experience in the Vicente Ferrer Foundation. Digital image management in a communication department of an NGO for Development (NGDO) is explained.

\section{Keywords}

NGO, NGDO, Third Sector, Documentary photography, Photo archives, Inmagic, Vicente Ferrer Foundation, Photography, Digital images, Photographic management, Photo edition.

Alonso-Fernández, Juan. "Gestión y conservación de documentos fotográficos en el Tercer Sector: experiencia de la Fundación Vicente Ferrer". El profesional de la información, 2011, julio-agosto, v. 20, n. 4, pp. 444-447.

http://dx.doi.org/10.3145/epi.2011.jul.12

“La fotografía podría ser esa tenue luz que modestamente nos ayudará a cambiar las cosas” Eugene Smith

\section{Introducción}

La importancia de la imagen fija es indiscutible. Como dice Del-Valle-Gastaminza", la fotografía "representa la memo- ria visual de los siglos XIX y XX y es un medio de representación y comunicación fundamental". La imagen registra situaciones, transmite valores, genera cultura y en algunos casos ayuda a transformar realidades. Recordemos en este

Artículo recibido el 28-04-11

Aceptación definitiva: 06-06-11 
sentido trabajos como Vietnam Inc, de Philip Jones-Griffiths o la fotografía social de Lewis Hine o Jacob Riis. Si además nuestro ámbito es el Tercer Sector, nuestra responsabilidad hacia una correcta gestión de la imagen se incrementa. Como agentes sociales de referencia, las ONGs tienen una obligación moral a la hora de representar gráficamente las realidades de los países en vías de desarrollo².

Las ONGs tienen una obligación moral a la hora de representar gráficamente las realidades de los países en vías de desarrollo

Si consideramos el snapshot (instantánea sin pretensiones) de George Eastman (fundador de Kodak en 1892) como una primera gran revolución visual en el sentido de que democratiza el acceso a la producción fotográfica, dicha extensión social se multiplica con la aparición de la tecnología digital. Susan Sontag ya advertía en los 70 que "la necesidad de confirmar la realidad y enfatizar la experiencia mediante fotografías es un consumismo estético al que hoy todos son adictos"3. El éxito de las cámaras digitales y los móviles con cámara acentúan una sobreproducción visual y como indica Luis Pavão "hoy el mundo tiene más fotografías de las que puede consumir"4. En este nuevo contexto, las organizaciones, los archivos fotográficos, deben aprender a trabajar con importantes volúmenes de documentos digitales y contar con profesionales que sepan valorar con criterio y rapidez las fotografías y los reportajes. Si el entorno es, como en este caso, un departamento de comunicación, la agilidad y la inmediatez se hacen imprescindibles.

En este artículo se presenta el caso de un archivo fotográfico del Tercer Sector en base a la experiencia de la Fundación Vicente Ferrer prestando especial atención a la gestión de la imagen digital. Basaremos nuestra explicación en la estructura de la tradicional cadena documental: entrada, tratamiento y salida. Como archivo de una entidad sin ánimo de lucro se encuentra en un estado intermedio entre el archivo puramente patrimonial y el archivo fotográfico de carácter editorial. La adaptación a este "limbo" particular ha determinado la mayoría de las decisiones que se han tomado.

\section{El archivo fotográfico}

Se encuentra integrado en el departamento de comunicación de la propia organización. Conserva y gestiona imágenes sobre el trabajo de la Fundación Vicente Ferrer y responde a las necesidades de información de carácter visual a la vez que promueve y participa en las diferentes estrategias de difusión fotográfica. El documentalista recibe, selecciona, prepara para la ingesta, digitaliza, clasifica, conserva, preserva, gestiona los derechos de autor, satisface peticiones, propone y edita reportajes y proyectos de difusión y se responsabiliza de forma completa de todos los contenidos visuales de la organización.

\section{Entrada}

Las fotografías provienen de cinco tipos de productores:
1. fotógrafos profesionales en plantilla;

2.fotógrafos profesionales que viajan de forma freelance a India;

3.fotógrafos profesionales contratados por la Fundación para reportajes determinados;

4. fotógrafos aficionados (visitantes, socios o trabajadores de la Fundación);

5.fotógrafos profesionales contratados por terceros que acompañan a empresas o instituciones en su visita a los proyectos de desarrollo.

Todas las fotografías que se reciben deben ir asociadas a un contrato donde, tras la correspondiente negociación con el autor, se especifican los posibles usos de las mismas. La Fundación respeta los derechos de autor contemplados en la Ley de propiedad intelectual de 1996 por un evidente tema legal pero también por una cuestión de deferencia y reconocimiento profesional hacia el fotógrafo y su trabajo.

La mayoría de las fotografías se reciben en soporte óptico (CD, DVD) y, en su defecto, vía ftp. Sigue habiendo cesiones de diapositivas, negativos y papel de material antiguo pero son casos puntuales. Si se acepta el ingreso de los documentos se realiza el correspondiente asiento. Esto tiene dos finalidades: dejar constancia escrita de los ingresos de documentación e identificar cada uno de los fondos que van a ser gestionados por la Fundación para evitar que se pierda su integridad, respetando así el principio de procedencia de Natalis de Wailly según el cual los documentos producidos por una institución u organismo no deben mezclarse con los de otra.

Una vez en el archivo se procede a la selección del material según dos criterios: técnico y política visual. Así, se descartan las imágenes técnicamente muy incorrectas (fuera de foco, trepidadas, oscuras o sobreexpuestas, repetitivas y $\sin$ contextualización informativa, entre otros). No se trata de un ensalzamiento de aspectos formalistas específicos sino de apostar por una calidad estética e informativa para la edición gráfica.

La correcta selección, indexación y sali$\mathrm{da}$, vienen determinadas por la capacidad analítica y sintética del documentalista, su dominio de la terminología fotográfica y su cultura visual

Por otro lado, como medio de una ONG, existe una política de comunicación visual basada en unos códigos deontológicos y especialmente en el Código de Imágenes y Mensajes a propósito del Tercer Mundo aprobado por la Asamblea General del Comité de Enlace de las Organizaciones No Gubernamentales Europeas ante la CE en 1989. En la Fundación se rechazan las imágenes con estereotipos y se apuesta por una fotografía que acerque a la realidad y a la riqueza cultural de los grupos desfavorecidos. Los estereotipos responden a imágenes preconcebidas en nuestro imaginario, muchas veces enraizadas en el subconsciente de las sociedades más desarrolladas. Imágenes cliché que simplifican una realidad y no ayudan a comprender la complejidad del 
mundo, en este caso, de la India rural. Como indica Rebeca Martín "el imaginario icónico colectivo del Tercer Mundo ha pasado en épocas anteriores por la imagen de las comunidades asoladas por los conflictos étnicos y armados, los desastres naturales o por la infancia desnutrida. El abuso de estas fotografías en los medios de comunicación de los países desarrollados crea una imagen distorsionada de los que están en vías de desarrollo ya que obvia las causas de la pobreza y contribuye al fomento de los estereotipos" (Martín-Nieto, 2009, p. 156).

Se trata, por tanto, de ofrecer fotografías que aporten información sobre la forma de vida y la cultura de las personas del Tercer Mundo: su entorno, su día a día, sus rituales, sus deseos, sus creencias... Representaciones que nos ayuden a comprender sus situaciones y sus necesidades. Se intenta huir de la imagen paternalista y ofrecer un contexto más fiel: se observa a los beneficiarios en su entorno natural, trabajando, relacionándose, realizando actividades cotidianas, siendo protagonistas de su propio desarrollo. En definitiva, se valoran aquellas imágenes que no inciten a la lástima o la caridad sino que promuevan la reflexión desde una representación constructiva y respetuosa.

El documentalista ha de ejercer una función de editor gráfico teniendo en cuenta para quién está trabajando y en qué línea comunicativa. Las decisiones deben ir guiadas por el criterio profesional, entendiéndolo como el conjunto de normas a aplicar para valorar una fotografía o reportaje ${ }^{5}$. Es importante la capacidad del documentalista para leer imágenes, mucho más allá de sus elementos de denotación pura, sabiendo detectar géneros, identificando discursos visuales y comprendiendo, desde su inherente subjetividad, las diferentes opiniones fotográficas sobre el mundo. El hecho de que la producción fotográfica sea en soporte digital ha llevado a adoptar algunos aspectos de OAIS (open archival information system), modelo funcional nacido de la nueva realidad tecnológica. De esta forma, después de la selección se convierte el llamado SIP (submission information package) u objeto digital que proviene directamente del productor, a AIP (archival information package), lo que sería el máster de archivo definitivo. Si es necesario se modifica el fichero digital y se renombra, siempre teniendo en cuenta la conservación permanente. Sobre todo, antes de una entrega de material, se intenta negociar con el productor tratando que el SIP sea lo más parecido posible al máster digital o AIP.

El documentalista recibe, selecciona, digitaliza, clasifica, conserva, preserva, gestiona los derechos de autor

\section{Tratamiento}

Se vio la necesidad de crear un sistema que permitiera migrar de forma rápida la información digital a hardware y software más modernos, optando para ello por una combinación de soportes magnéticos y ópticos. El archivo cuenta con una cabina de discos duros con copia de seguridad periódica en una cinta magnética alojada en un lugar externo.
A su vez existe otra copia de seguridad en una colección de DVD's. Estas unidades ópticas realizan también la función de las antiguas cajas fotográficas del archivo tradicional. Cada DVD representa una parcelación lógica de la información en 4,5 GB. Esto permite dotar de mayor estructuración y orden al fondo.

La elección del AIP fue compleja ya que las necesidades son muy variadas. La voluntad de ser un archivo de carácter patrimonial en una institución con más de 40 años de historia, aconsejó el tiff como formato máster ideal. Sin embargo la faceta de archivo de comunicación y sus características (gran volumen de un fondo en constante crecimiento y recursos materiales disponibles) exigía rapidez en el trabajo y optimización del espacio. Finalmente se optó, en la mayoría de los casos, por el jpeg de primera generación como el usado por la Agencia EFE. Con este formato se resuelven la mayoría de las peticiones y una correcta conservación y gestión elimina los riesgos de la degradación de la compresión. Sin embargo, en ocasiones, por tratarse de determinados reportajes de gran calidad, se conserva el tiff.

El documentalista ha de ejercer como editor gráfico teniendo en cuenta para quién está trabajando y en qué línea comunicativa

Se utiliza el sistema de gestión de bases de datos (sgbd) Inmagic con una configuración ad hoc. Se cataloga según la normativa ISBD (International standard bibliographic description) y Aacr2 (Anglo-American cataloguing rules, 2nd ed.). El contenido se indiza con un lenguaje documental de descriptores controlados. Basándose en los usuarios, la temática del fondo y el grado de descripción documental acordado, se redactó un manual de indexación con una normativa que dota a la operación de una coherencia y una especificidad que busca mejorar la recuperación. Para reducir el enorme trabajo que supone un archivo de estas características, se decidió incluir en el campo "Tipo de registro" (que incluye: "Fotografía única", "Fotografía principal con asociadas" o "Reportajes") el descriptor "Reportajes". A diferencia de "Fotografía principal con asociadas" que podría ser una pequeña serie de un momento y motivo concretos, "Reportajes" es el conjunto de imágenes que, mediante una narrativa o algún leitmotiv visual, muestran un acto (inauguraciones, exposiciones, encuentros, entregas de premios, stands, manifestaciones...) o tema concreto con una mirada determinada. Un reportaje es, por ejemplo, la inauguración del Hospital Pediátrico en la localidad de Bathalapalli. Esto permite agrupar en un solo registro un conjunto de imágenes con un tema determinado.

\section{Salida}

La salida de las imágenes se produce por dos motivos: uno reactivo, que responde a las necesidades informativas de la organización y otro más proactivo vinculado a la configuración y participación en políticas de difusión.

En el primer caso, en base a su destino final, el criterio profe- 
sional debe valorar aspectos morfológicos, de contenido y semánticos, dotando a la imagen polisémica de un sentido más o menos unívoco y consciente. Las demandas son muy variadas y pueden ir desde fotografías para ilustrar la formulación de un proyecto financiado por una institución pública a imágenes para un reportaje en un medio de comunicación, entre otros. El uso va a determinar tanto las características físicas, el modo de entrega, como el contenido estético e informativo de la imagen. No será lo mismo una imagen para un póster corporativo de $90 \times 60 \mathrm{~cm}$ que para una web de una empresa colaboradora. La primera necesitaría una resolución de 300 dpi (puntos por pulgada) mientras la segunda se puede resolver con $72 \mathrm{dpi}$. Esto también determina la entrega ya que mientras la segunda se puede adjuntar a un correo electrónico, la primera deberá enviarse vía FTP o en soporte óptico por correo postal o mensajero.

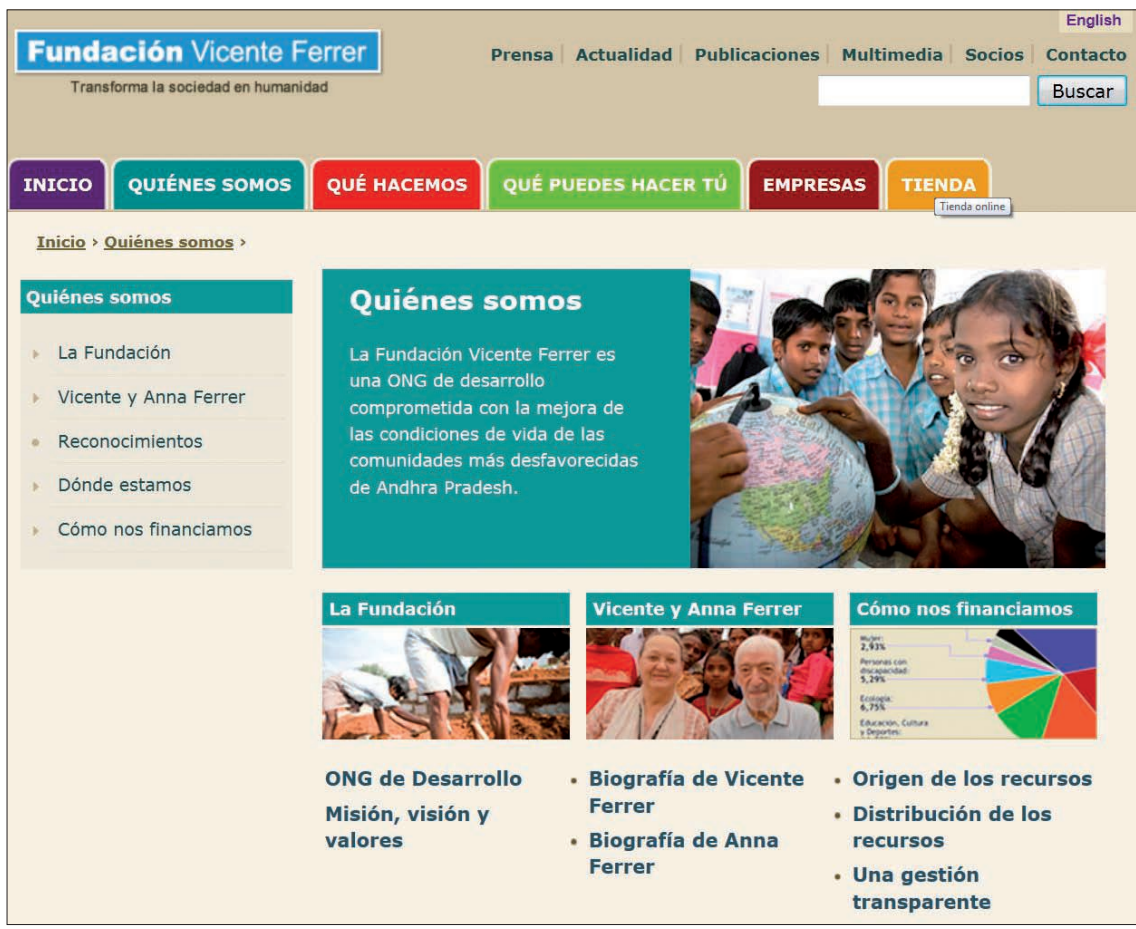

http://www.fundacionvicenteferrer.org
Es diferente también la selección de una petición para una puesta en página de seis imágenes que para una sola imagen. En el primer caso se pueden mostrar varios aspectos e incluso establecer cierta narrativa, mientras que en el segundo se ha de condensar todo el mensaje en una fotografía.

\section{El trabajo del profesional en un archivo fotográfico viene marcado por el respeto hacia lo visual como medio de expresión}

El segundo motivo, más proactivo, responde al propósito de rentabilizar de la mejor forma posible las diferentes estrategias de gestión y divulgación del fondo documental. Se trata de mover las imágenes evitando su encierro en el archivo, promoviendo a su vez una cultura fotográfica reflexiva y documental. El profesional debe detectar carencias, plantear nuevas iniciativas de difusión y proponer reportajes. Exposiciones, mesas redondas, conferencias, proyecciones, son algunos ejemplos.

\section{Conclusiones}

Los nuevos entornos digitales representan una mayor producción y lectura de fotografías. Existe una gran variedad de archivos fotográficos. Muchos de ellos se hallan en una situación particular donde, debido al flujo de trabajo o a los recursos disponibles, es complicado aplicar la lógica que rige las instituciones patrimoniales. La correcta gestión de los documentos visuales exige especialización y una adaptación propia de procesos y equipos que considere normativas, recursos, tipo de organización, fondo, usuarios y objetivos. El análisis de caso ha de determinar el modelo.

En esta nota hemos compartido un tipo aplicable a una situación particular: la imagen digital en un medio de comuni- cación de una organización sin ánimo de lucro. La capacidad analítica y sintética del documentalista así como su dominio de la terminología fotográfica y, en general, su cultura visual son aspectos importantes que determinan una correcta selección, indexación y salida. La potencia del lenguaje fotográfico se explota desde una edición gráfica profesional que optimice recursos y garantice calidad y coherencia. Es sobre todo el respeto conceptual hacia lo visual como medio de expresión en sí mismo lo que ha de pautar el flujo de trabajo. Además, en una organización del Tercer Sector la responsabilidad hacia una correcta comunicación gráfica se hace extensiva a un compromiso tácito con los beneficiarios, los colaboradores y el colectivo profesional.

\section{Fundacion-Vicente-Ferrer.jpg http://www.fundacionvicenteferrer.org}

\section{Bibliografía citada}

1. Del-Valle-Gastaminza, Félix (ed.). Manual de documentación fotográfica. Madrid: Síntesis, DL 1999, p. 13.

2. Martín-Nieto, Rebeca. "El Tercer Mundo representado: la imagen como nido de estereotipos". Icono14, 2009, noviembre, n. 13, pp. 155.

http://www.icono14.net/revista/num13/8_icono13_rebeca martin.pdf

3. Sontag, Susan. Sobre la fotografía. Barcelona, Edhasa, 1981, p. 34.

4. Pavão, Luis. Conservación de colecciones fotográficas. Granada: Junta de Andalucía, Consejería de Cultura: Comares, 2001, p. 17.

5. Vila, Maria-Rosa. "Lectura fotográfica. Los procesos de valoración en fotografía”. Enfocant, 14 marzo 2010.

http://enfocant.blogspot.com/2010/03/els-processos-devaloracio-en.html 